\title{
Striking a balance
}

\author{
Staff across 74 UK universities are striking because pay and working conditions are eroding, and changes to the \\ pension scheme mean that workers fear they are paying in more money for fewer benefits without good reason. \\ More clarity is needed.
}

$\Lambda$ cademics generally work long hours and tenured positions are limited in number. Many young researchers progress through a series of temporary contracts that tend to make them put their lives on hold (in terms of starting a family or purchasing a home) until they get a permanent contract or leave academia. But at least they can then look forward to a decent retirement. Or can they?

Unfortunately, conditions are such that even tenured professors are concerned about their working life and projected retirement. Staff at UK universities have been striking (on and off) since November 2019 in response to a new set of proposals from employers. University and College Union (UCU) members of 60 universities across the UK have been taking industrial action over two separate disputes regarding pensions, and pay and working conditions. The Universities Superannuation Scheme (USS) is the only pension scheme available to academics. In 2011, there was a seismic adjustment to the scheme after the global financial meltdown of 2008, which closed the final salary scheme to new members, reduced and capped growth, and increased contributions from members that effectively gave new joiners an $11 \%$ drop in total compensation compared to pre-2011 entrants.

Then, in 2016, a revaluation of the scheme brought in further changes to plug the projected shortfall: the closure of the final salary pension scheme, the introduction of a cap on benefitable salary $(£ 55,000)$ and an increase to $8 \%$ for employee contributions (with employers' contributions increasing to $18 \%)$. Further changes for 2019 were proposed, which among other things would disproportionately affect senior academics. These proposals were opposed by UCU, who made counterproposals that were ignored, and strike action ensued in February and March 2018. Following those strikes, contributions from employers and employees were increased and, moreover, projected to further increase in 2019, which brings us to the last round of strikes.

The grievances go beyond pension reform; workers have had enough of the culture of overworking and the concomitant mental health issues. To see why working conditions are a problem, consider that $34 \%$ of academic staff are on fixed-term contracts, $13 \%$ are paid by the hour (mostly part-time workers) and $2 \%$ have zero hours contracts. These numbers have not changed much year on year. Add to that the gender pay gap, which for 2019 was $15.1 \%$; in other words, women in the same position as men earn less, despite 40 -year-old equal pay legislation. Black and minority ethnic staff are paid $9 \%$ less than their white counterparts. (Apart from the gender pay gap, the data are from the 2017/2018 academic year.)

Between the union and the pension scheme lies the third player, the employers. They are represented by Universities UK (UUK) and the Universities and Colleges Employers Association (UCEA). Their website refers to a series of tripartite talks that have led to "positive proposals .. addressing the concerns raised by trade unions on contractual arrangements, workload and mental health, and gender pay gap and ethnicity pay" that make the continued "industrial action disappointing".

UCU members interpreted those proposals differently. As the eight-day strike in November 2019 ended in stalemate, the union chose to apply more pressure. In February and March this year, staff at 14 additional universities joined in the strike action, bringing the total number of institutions to 74 , or just over half of all 147 UK institutions involved. The latest 14-day industrial action will end on 13 March. Further tripartite talks have been scheduled into April.

As Nature Astronomy goes to press, all sides remain entrenched. Workers are understandably upset that they have been getting below-inflation salary increases and the pension outlook is worse than what they signed up for. They want any increases in contribution to the scheme to be shouldered by the institutions, which are perceived to be investing in flashy new buildings and farflung university campuses. The universities claim that paying even more would lead to cuts elsewhere that would erode teaching, services and research. Both sides are anxious that disruptions to teaching are kept to a minimum. So far, students have been supportive of the strikes, but with repeated cancellations of lectures, the absence of tutorials and the looming exam season, patience could wear thin.
That leaves the USS, which insists that the changes are necessary in order to safeguard the fund. According to cosmologist Andrew Jaffe of Imperial College London, a major problem is the lack of transparency. Academics have to take the USS-predicted shortfall on faith. The official calculations are not available and the general feeling among workers is that the models may be too conservative, requiring the scheme to be robust against sector-wide failure (which would mean that a swathe of universities would have to go out of business). Realistic models put to the employers have been ignored; UUK is preparing to release "a new set of transparency guidelines which should make information about the scheme and valuations more widely available".

Whatever happens, the fact is that academic jobs are not the 'safe jobs-for-life that don't pay particularly well but guarantee a nice pension' that many students once thought. Is there a point, then, in pursuing a postgraduate degree and several years of postdocs with no job security? Jaffe takes a pragmatic view. It was always the case that not every graduate student would make it as a professor. He says that departments are more open about that now, and he is happy to train good thinkers for any job. Many graduates apply their astrostatistics expertise to the growing area of data science, for instance. Meanwhile, he is striking so that those who do stay in academia have a better future.

Striking over pension reform is not just a problem in the UK. In France, Emmanuel Macron's attempt to overhaul the French pension system from 42 separate pension schemes to one universal points-based system has stoked fierce resistance from the unions since last December, with large-scale demonstrations and rolling strikes, which could go on for months, if only sporadically. As is the case for the UK strikers, the French workers complain about a lack of transparency, as the government's proposed increase in retirement age came out of the blue for the public. People can accept change if it's strictly necessary and well-explained. Otherwise, they feel that the powerful are taking advantage of those with less power.

Published online: 12 March 2020 https://doi.org/10.1038/s41550-020-1061-z 